\title{
A obra de Boltzmann em Física
}

(Boltzmann's work in Physics)

\author{
Sílvio R. Dahmen ${ }^{1}$ \\ Instituto de Física, Universidade Federal do Rio Grande do Sul, Porto Alegre, RS, Brasil \\ Institut für Theoretische Physik III, Universität Würzburg, Alemanha
}

\begin{abstract}
O objetivo do presente trabalho é proporcionar uma visão geral sobre a obra de Boltzmann em Física. Algumas de suas contribuições mais importantes são discutidas e contextualizadas.

Palavras-chave: História da Física, Boltzmann.
\end{abstract}

The goal of the present work is to present an overview of Boltzmann's work in Physics. Some of his most significant contributions are discussed and contextualized.

Keywords: History of Physics, Boltzmann.

\section{Introdução}

Há 100 anos, mais precisamente no dia 05 de setembro de 1906, quando se encontrava em repouso em Duino, Boltzmann pôs fim à própria vida. Este ato, considerado por muitos o trágico desfecho para o criador de uma obra que havia colhido entre outras coisas a incompreensão de seus pares e estivera sujeita a constantes ataques não parece condizer com o quadro que podemos traçar a partir de uma leitura mais detalhada de sua biografia: Boltzmann, enquanto professor e pesquisador, tivera em vida o reconhecimento reservado a poucos. Com um início de carreira precoce - aos 25 anos já era professor titular de física matemática em Graz - considerado por muitos um dos maiores cientistas austríacos, Boltzmann não apenas foi convidado a assumir a cadeira de física teórica em grandes centros, notadamente Berlim, como também foi agraciado com vários títulos honoríficos, chegando a renunciar à troca do nome para von Boltzmann ${ }^{2}[1$. Não obstante todo o reconhecimento, suas freqüentes mudanças de estadode-espírito, por ele jocosamente atribuídas ao fato de ter nascido na noite da Terça-Feira-Gorda para QuartaFeira-de-Cinzas, bem como a inquietude que parece ter caracterizado seus últimos anos de vida apontam na direção de um grave quadro de saúde, que teria se de- teriorado ainda mais em função de um intenso rítmo de trabalho e uma série de cansativas viagens pelos Estados Unidos ${ }^{3}$.

Se hoje, passados 100 anos de sua morte, nos lembramos de Ludwig Eduard Boltzmann acima de tudo como um dos criadores da mecânica estatística, sua obra em Física é tão multifacetada quanto multifacetados foram seus interesses - e aí esteja talvez a chave para que o compreendamos. Boltzmann era um pensador original e sua obra em mecânica estatística, em particular os primeiros artigos entre 1866 e 1872, são ainda hoje motivo de estudos e polêmica sobre o quanto ou o quê Boltzmann realmente fez: se por um lado alguns defendem que ele tenha apenas generalizado os trabalhos de Maxwell 11, para outros historiadores Boltzmann mostra uma visão totalmente nova dos métodos e idéias da ciência que ajudou a fundar 4, 5, 6. Com respeito a sua produção em Física, a seção final deste artigo, compilada a partir dos três volumes das obras coligidas 7] nos dá uma idéia de sua produção intelectual ao longo de 41 anos de trabalho como pesquisador e professor. Nesta compilação há diversos pontos dignos de nota. A primeira diz respeito à abrangência dos temas tratados, como já pude citar acima: trabalhos experimentais em eletromagnetismo, teoremas matemáticos sobre séries de Fourier, artigos de cunho filosófico e

\footnotetext{
${ }^{1}$ E-mail: dahmen@if.ufrg.br.

Copyright by the Sociedade Brasileira de Física. Printed in Brazil.

${ }^{2} \mathrm{Na}$ Alemanha e Áustria títulos nobiliárquicos conferidos por mérito são acompanhados pelo acréscimo de um von ao sobrenome. Quanto a isto, Boltzmann se manifestou dizendo: "Se nosso nome tão classe-média foi suficiente para meus antepassados, ele continuará sendo para meus filhos e netos".

${ }^{3} \mathrm{Em}$ seus últimos anos de vida Boltzmann também passou a sofrer da perda progressiva da visão, necessitando da ajuda de uma assistente para ler 2]. Entre as outras possíveis causas de seu suicídio estariam uma auto-recriminação por não ter trabalhado o suficiente na finalização de suas idéias e o medo de perder a capacidade de trabalho [2, 3]. Com relação à questão da finalização de idéias, ver comentários na primeira seção, quando discuto o tema Gibbs em contraposição a Boltzmann.
} 
histórico, livros, elegias e resenhas. Segundo, a porção mais significativa de sua produção intelectual é voltada à termodinâmica e à teoria cinética, o que o torna, de longe, o mais profícuo entre os fundadores da mecânica estatística. Muitos de seus artigos são longos tratados, não raro com mais de 100 páginas, uma característica pela qual inclusive muitos de seus pares o consideravam um autor difícil, como Maxwell pôde certa vez expressar em carta a Lorentz [8], e talvez o motivo pelo qual poucos compreendiam sua obra. Isto explica também a dificuldade em se classificar os trabalhos de Boltzmann por áreas temáticas, uma vez que em um mesmo tratado vários assuntos eram por vezes abordados. Assim, um grande conhecedor da obra de Boltzmann como S. G. Brush considera apenas 57 de um total de 79 artigos como realmente relacionados de algum modo à teoria cinética, enquanto Hasenöhrl, editor dos trabalhos coligidos de Boltzmann e seu aluno, coloca este número em 67 [6]. Embora contemporâneo de grandes nomes da ciência do século XIX, com os quais manteve intensa correspondência, na questão da abrangência de interesses Boltzmann parece pertencer a uma classe à parte [5]. Explicar o fenômeno Boltzmann à luz de uma análise estritamente científica, desprezando aspectos históricos e sociais, está certamente fadado ao insucesso. Boltzmann foi, em grande medida, retrato fiel do país e da época em que viveu, um período da história marcado por grandes revoluções científicas, tecnológicas e políticas. Para Klein, Boltzmann foi um dos maiores atores do grande embate científico-filosófico do final século XIX: a legitimidade da fundamentação da natureza sobre uma visão mecanicista (e atomística) da matéria em contraposição a outros credos, em particular o Energetismo de Helm e Ostwald [8]. Na qualidade de grande polemicista e debatedor [9, ele tomou parte ativa nas grandes questões científicas e tecnológicas do século XIX, em particular naquela que ainda hoje é presente: a teoria da evolução de Darwin. Sua admiração pelo naturalista inglês era tanta que ele chegou a afirmar que o século XIX entraria para a história como o século de Darwin [10]. Sua admiração pela então nascente aviação levou-o a acompanhar os experimentos de Otto Lilienthal e a escolher a aviação como tema de sua palestra num importante evento científico em 1894 em Viena 11. Isto também nos mostra uma outra face de Boltzmann: o uso consciente de seu status como promulgador de idéias e divulgador científico.

Como professor universitário do Império AustroHúngaro, Boltzmann viveu um período único da história de seu país: a derrota para a Prússia em 1866 pôs um fim à hegemonia do império Habsburgo sobre o mundo germânico e foi o início de uma série de eventos que culminariam, 52 anos depois, no seu esfacelamento. Mas ele foi também um período de grandes mudanças no campo da cultura e da tecnologia. Se olharmos para a Viena de Boltzmann veremos que as marcas deixadas por seus artistas, escritores e cientistas ainda hoje estão presentes. O liberalismo político, consequência maior da derrota de 1866, se refletiu em diversas esferas da sociedade e permitiu, em particular, que as universidades vivessem um período de grande efervescência [6]. Em sua biografia de Boltzmann, M. Cercignani sugere uma interessante analogia entre a vida de Boltzmann e a sociedade descrita no livro Um Homem Sem Qualidades, de Robert Musil [12]. Este difícil romance descreve ao longo de suas quase 2000 páginas um retrato da sociedade do fictício país da Kakania ${ }^{4}$. Segundo Cercignani [1]:

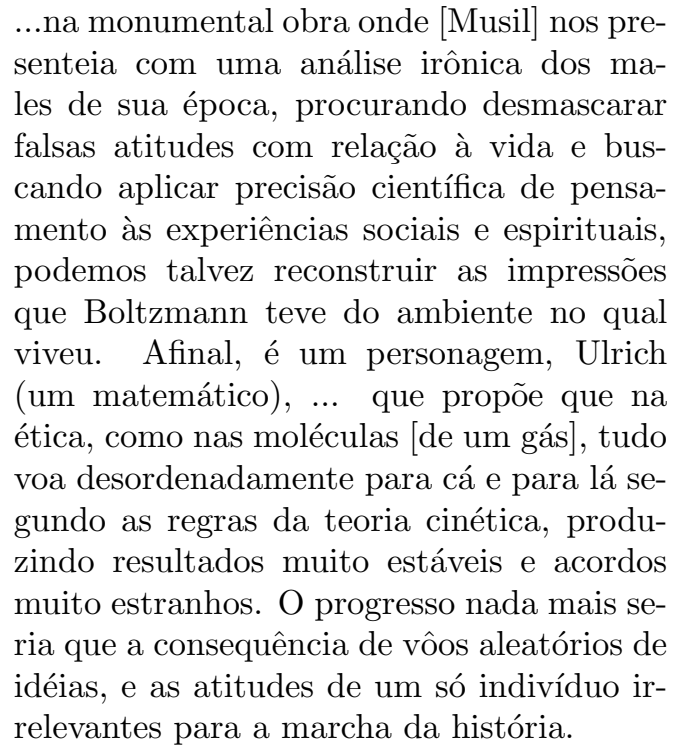

Por mais instigantes que estas considerações acima possam nos parecer, uma análise mais profunda nesta direção está além do escopo deste artigo. Gostaria assim de me restringir neste artigo a uma análise da obra de Boltzmann e às conseqüências da mesma sobre o edifício da Física. Esta tarefa, enquanto gratificante, é também cercada de desafios em função do volume e abrangência de sua obra, para a qual seria necessário um número de páginas muito além daquele que o espaço aqui me permite. Portanto, sem a pretensão de estar escrevendo um artigo definitivo, gostaria de apresentar aqui apenas um quadro geral, discutindo também importantes contribuições de Boltzmann em outras áreas mas que foram de um certo modo eclipsadas pelo seu trabalho em mecânica estatística. Procurei superar as limitações deste artigo (e também minhas enquanto teórico e não historiador) indicando uma literatura especializada onde o leitor poderá aprofundar-se

\footnotetext{
${ }^{4}$ Kakania é uma alegoria ao império austro-húngaro. O nome é derivado a partir das inicias $k . k$. (pronuncia-se ka-ka) para kaiserlichköniglich que significam imperial-real e sempre acompanhava os nomes de instituições do império. A pronúncia, em alemão, remete também à palavra kaka, utilizada por crianças ao se referirem a algo sujo. Musil, engenheiro por formação, doutorou-se em 1908 em Berlim com uma tese sobre a filosofia de E. Mach, grande opositor do credo atomístico. Como estudante em Viena certamente conhecia o trabalho de Boltzmann.
} 
neste ou naquele assunto que julgar mais interessante. Restringir-me-ei aqui ao cerne das idéias de Boltzmann e às múltiplas facetas de seu trabalho na seguinte ordem: (a) a mecânica estatística; (b) problemas experimentais em eletromagnetismo; (c) fundamentos da mecânica; (d) Boltzmann e a tecnologia; (e) como ler Boltzmann hoje, com particular ênfase nos textos originais e na literatura boltzmanniana.

\section{Boltzmann e a mecânica estatística}

Em 1866, ano da conclusão de seu doutorado, Boltzmann publicou um artigo intitulado "Acerca do significado mecânico da segunda lei da teoria do calor" onde, como o título bem coloca, ele tenta fundamentar a segunda lei através da aplicação de princípios mecânicos ao movimento das moléculas de um gás 16. Este fora o segundo artigo do jovem físico. No ano anterior ele havia publicado um trabalho acerca do "movimento da eletricidade em superfícies curvas", seu tema de doutorado sob a orientação de Josef Stefan [17. Por qual caminho teria Boltzmann sido conduzido ao problema da segunda lei?

A aplicação da mecânica para um gás de partículas tivera seus precursores: em 1738 Daniel Bernoulli levantou a hipótese que as propriedades de um gás, como pressão e temperatura, poderiam ser entendidas considerando um gás como um conjunto grande de moléculas elásticas que colidiam entre si e com as paredes do recipiente. A idéia obviamente não era nova, mas Bernoulli foi o primeiro a colocar a hipótese em termos quantitativos, lançando assim as bases do que viria a ser a teoria cinética de algumas décadas a frente. Entre os antecessores de Boltzmann podemos contar A. Krönig, que em 1856 deduziu a equação $P V=n R T$, e R. Clausius, que em 1857 mostrou de maneira clara que a energia térmica de um gás nada mais era que a energia cinética das moléculas. Em outras palavras, a primeira lei da termodinâmica nada mais era que uma lei da mecânica aplicada às partículas do gás [18. Mas foi J.C. Maxwell que, a partir das idéias de Simon, Lagrange, Bernoulli, Herschel, Krönig e Clausius desenvolveu em 1859 uma teoria para processos de transporte em gases, calculando entre outras coisas a viscosidade, a difusão e a transmissão de calor. Neste ano ele deduziu a lei de distribuição de velocidades das moléculas de um gás de um modo ainda um tanto heurístico e em 1867 de forma mais fundamentada. O mérito de Clausius e Maxwell foi mostrar que as propriedades de equilíbrio e de transporte seguem da cinética das moléculas. Mas se isto era possível, como explicar então a segunda lei? Sua formulação, na maneira como a conhecemos, baseia-se no conceito de entropia $S$ introduzido em 1865 por Clausius. A idéia é simples, ainda que o conceito de entropia um tanto obscuro: para todo estado de equilíbrio termodinâmico pode-se definir uma entropia $S$. Consideremos dois estados $z_{1}$ e $z_{2}$ quaisquer tais que $S\left(z_{2}\right)>S\left(z_{1}\right)$. Para qualquer transformação termodinâmica reversível que leva de $z_{1}$ a $z_{2}$ temos que $d S$ ao longo do processo é dado pela razão do calor $d Q$ fornecido ao sistema e a temperatura $T$ na qual isso ocorre: $d S=d Q / T$. A variação de entropia é então $\Delta S_{\text {rev }}=\left[S\left(z_{2}\right)-S\left(z_{1}\right)\right]_{\text {rev }}=\int_{z_{1}}^{z_{2}} d Q / T$. Para qualquer processo irreversível que nos leve de $z_{1}$ a $z_{2}$ a segunda lei diz que $\Delta S_{\text {irrev }}>\Delta S_{\text {rev }}$, ou seja, a processos irreversíveis está associado um aumento da entropia maior que aquele de processos reversíveis entre os mesmos estados. Podemos entender irreversibilidade aqui em seu sentido mais amplo: há na natureza um sentido preferencial do tempo para a maioria dos processos naturais, a chamada flecha do tempo (termo cunhado por Eddington em 1928). O "problema" da segunda lei então torna-se claro: se quisermos fundamentar a termodinâmica sobre uma teoria cinética, devemos ser capazes de explicar a segunda lei em termos cinéticos, sem a necessidade de introduzirmos hipóteses adicionais - a irreversibilidade deve surgir naturalmente das leis da mecânica. Mas se estas são reversíveis, surge então um paradoxo. Foi buscando uma resposta a esta pergunta que Boltzmann fez aquilo que, nas palavras de Schrödinger, representa seu maior legado à Física [19]: mostrar que aquilo que nos parece impossível, a reversibilidade dos fenômenos naturais, na verdade não é impossível, mas sim improvável. Nenhuma lei da Física é violada se os pedaços de um copo estilhaçado se juntarem novamente. Nunca vimos isso ocorrer apenas pelo fato que a probabilidade que isso ocorra é inimaginavelmente pequena. A segunda lei é assim uma lei probabilística. E aqui está a outra grande contribuição de Boltzmann à Física: a introdução do conceito de probabilidade como ingrediente fundamental para a descrição da natureza ${ }^{5}$

\footnotetext{
${ }^{5}$ Dois comentários acerca de probabilidade e irreversibilidade são pertinentes. Com relação à primeira, é necessário distinguir a probabilidade em Boltzmann e a probabilidade em física quântica. Embora nesta última ela seja, segundo a interpretação de Copenhague, intrínseca à natureza quântica, na mecânica clássica a introdução de conceitos probabilísticos requer uma justificativa. Afinal, é uma das premissas básicas da física clássica o fato de que conhecido o estado dinâmico de um sistema e as forças que sobre ele atuam é possível precisar exatamente seu futuro e tracejar seu passado, não importa quão complexo o sistema. Obviamente para a maioria dos sistemas de interesse o conhecimento de todas as variáveis dinâmicas é impossível enquanto fato mas não enquanto princípio. Embora Boltzmann não tenha se ocupado destas questões mais aprofundadamente, sua introdução em Física é tema de vários estudos [20]. Ao estendermos a mecânica estatística clássica de Boltzmann para a estatística quântica, os mesmos elementos probabilísticos se somam àqueles próprios da mecânica quântica. No que tange à flecha do tempo, especialistas no assunto costumam diferenciar entre irreversibilidade termodinâmica, cosmológica, quântica, da radiação, etc..Há a rigor diferentes flechas do tempo, mas a relação entre elas ou a questão se algumas delas nada mais são que casos particulares de outras ainda é tema de estudos [21, 22]. A questão da irreversibilidade pelo colapso da função de onda é vista como fruto da interação do meio com o objeto quântico, e não deve ser confundida com a teoria em si, reversível temporalmente.
} 
Boltzmann muito provavelmente chegou à teoria cinética através de Maxwell, posto que Stefan era um profundo conhecedor da teoria eletromagnética [23]. Grande admirador de Maxwell, cujos trabalhos em eletromagnetismo ele ajudou a popularizar no continente europeu, Boltzmann certamente conhecia os trabalhos deste sobre teoria cinética de 1859 e 1867, pois já em 1868 [24] o cita em seu trabalho onde se volta para o problema da distribuição de velocidades das moléculas de um gás. A partir deste trabalho Boltzmann deu início a um longo programa que o levaria a generalizar o trabalho de Maxwell sobre distribuição de velocidades para o caso geral de moléculas poliatômicas interagentes, razão pela qual a conhecemos hoje como "distribuição de Maxwell-Boltzmann". Com estes trabalhos Boltzmann aprofundou-se na técnica desenvolvida por Maxwell para dar, em 1872, o grande passo: deduzir a segunda lei a partir das propriedades de uma equação que hoje recebe seu nome. Esta dedução é conhecida como o teorema $\mathrm{H}$.

\subsection{O teorema $\mathrm{H}$ e a irreversibilidade}

Em sua primeira tentativa de provar a segunda lei, em 1866, Boltzmann colocou em termos bem explícitos aonde queria chegar [16]:

O objetivo do presente artigo é estabelecer uma prova puramente analítica e geral da segunda lei da termodinâmica, bem como descobrir o teorema da mecânica que a ela corresponde.

Seus resultados foram no entanto bem mais modestos que o objetivo proposto. Primeiro sua argumentação era restrita a sistemas gasosos e não tão gerais como almejado. Porém, para conseguir provar a segunda lei ele foi obrigado a fazer uma forte restrição ao movimento das moléculas: ele tinha que ser periódico. Com isto ele foi capaz de deduzir um teorema a partir de uma generalização do princípio da ação mínima e chegar a uma expressão para a entropia na forma (notação original):

$$
S=2 \sum \log \int_{t_{1}}^{t_{2}} \frac{m c^{2}}{2} d t+\text { const } .
$$

Aqui log é o logaritmo natural, $c$ a velocidade de uma molécula e a soma se estende sobre todas as moléculas. Para que um sistema seja periódico, Boltzmann argumenta que pode-se tomar a diferença $t_{2}-t_{1}$ com sendo um período $\tau$ e então interpretar a integral como sendo o produto de $\tau$ pela temperatura média da partícula (Boltzmann identifica temperatura com energia cinética - a constante de Boltzmann $k_{B}$ só foi introduzida mais tarde por Planck). Caso o sistema não seja periódico Boltzmann argumenta, de maneira um tanto quanto evasiva, que se as órbitas não se fecham em tempo finito, então podemos imaginá-las como se fechando num tempo infinito. Aqui os especialistas divergem: Klein considera esta condição uma fraqueza do trabalho original 8. Badino discorda, afirmando que isto não representa um handicap do programa boltzmanniano 44. Na minha opinião trata-se apenas de uma questão de interpretação do texto de Boltzmann, muitas vezes difícil.

Mas o trabalho de Maxwell de 1867 e assim sua influência sobre Boltzmann foi fundamental, pois foi por meio dele que Boltzmann adotou uma postura totalmente diversa daquela de seu artigo de 1866: abandonar o uso do conjunto completo de variáveis dinâmicas que descrevem o sistema de moléculas em favor de uma função de distribuição de velocidades moleculares. Entre 1868 e 1871 Boltzmann publicou uma série de trabalhos onde não apenas fez sua a técnica desenvolvida por Maxwell como a estendeu consideravelmente. Mas, mais do que isso, foi nesta série de trabalhos que Boltzmann generalizou o teorema da equipartição da energia [24] e, do ponto de vista dos frutos futuros, lançou as sementes de um problema que ainda hoje representa uma grande área de pesquisa: a hipótese ergódica. O cerne da questão está na interpretação física da função de distribuição de velocidades $f(\vec{r}, \vec{v}, t)$ que, segundo Maxwell, representa uma densidade de probabilidade: em outras palavras, $f(\vec{r}, \vec{v}, t) d x d y d z$ é o número de moléculas num elemento de volume $d V=d x d y d z \mathrm{cu}-$ jas velocidades se encontram entre $\mathbf{v}$ e $\mathbf{v}+\mathrm{d} \mathbf{v}$ num dado instante $t$. Para Boltzmann $f$ pode não apenas ser interpretada de acordo com Maxwell como também ela pode ser vista como a fração de tempo de um intervalo longo o suficiente durante o qual a velocidade de uma molécula qualquer está dentro destes mesmos limites 8. Em outras palavras, se olharmos um grande sistema de muitas moléculas em um dado instante e de alguma maneira pudermos medir a fração de moléculas num dado entorno que tenham tais velocidades obteremos o mesmo resultado se esperarmos um tempo suficientemente longo e contarmos quantas moléculas passaram por ali com tais velocidades dividido pela média temporal do número total de moléculas naquele ponto. Que estas duas interpretações sejam equivalentes não apenas é uma questão nada trivial, e Boltzmann sabia disto, como ela é fundamental para os fundamentos da mecânica estatística enquanto área, embora isto seja um ponto altamente discutível até os dias atuais 25]. Boltzmann argumentou que a hipótese era fisicamente plausível e com isso encerrou o assunto. O nome hipótese ergódica foi introduzido apenas em 1911 por Paul e Tatyana Ehrenfest [26.

O ano de 1872 marca a data na qual Boltzmann publicou aquele que é para muitos seu mais importante trabalho em mecânica estatística [27. Este julgamento obviamente reflete muito as preferências de quem o faz,

\footnotetext{
${ }^{6} \mathrm{O}$ título se deve provavelmente ao fato de que Boltzmann, ao obter os resultados, queria publicar um artigo curto nos Annalen der Physik para garantir a prioridade sobre os mesmos, enviando depois um artigo mais longo e detalhado. Como Stefan, seu mentor
} 
mas sem qualquer sombra de dúvida o título "Estudos adicionais acerca do equilíbrio termodinâmico entre moléculas de um gás" do longo tratado de mais de 100 páginas não faz juz à importância de seus resultados 6 . O objetivo de Boltzmann neste e nos tratados anteriores era estudar a natureza do equilíbrio termodinâmico - o termo aparece no título de todos eles - em particular, provar a unicidade da distribuição de Maxwell para a descrição de estados de equilíbrio. Maxwell já mostrara que sua distribuição era estacionária, ou seja, era não se alterava em função de eventuais colisões entre partículas, mas para Boltzmann ...no entanto isto não prova que, qualquer que seja o estado inicial do gás, ele sempre tenderá para o limite encontrado por Maxwell 27.

$\mathrm{Na}$ primeira parte do artigo de 1872 Boltzmann estuda a influência das colisões na dinâmica da função de distribuição para o caso de um sistema homogêneo, ou seja $f$ só depende das velocidades das partículas e não de sua posição. Para isto ele usa o famoso Stosszahlansatz de Clausius, a hipótese sobre o número de colisões num intervalo de tempo $\tau$. Segundo a hipótese o número de colisões nas quais uma molécula $\mathrm{A}$ de energia cinética entre $x$ e $x+d x$ colide com um molécula $\mathrm{B}$ de energia entre $x^{\prime}$ e $x^{\prime}+d x^{\prime}$ de modo que ao final uma delas tem energia entre $\xi$ e $\xi+d \xi$ é dado por ${ }^{7}$ :

$$
d n=\tau f(x, t) d x f\left(x^{\prime}, t\right) d x^{\prime} d \xi \psi\left(x, x^{\prime}, \xi\right) .
$$

A energia de B após o choque não aparece pois devido à conservação de energia $x+x^{\prime}=\xi+\xi^{\prime}$. Também $f(x, t) d x$ representa o número de moléculas por unidade de volume cuja energia está entre $x$ e $x+d x$ (o mesmo valendo para $\left.x^{\prime}\right)$. O termo $d \xi \psi\left(x, x^{\prime}, \xi\right)$ é um fator de proporcionalidade onde $\psi$ depende das características do choque, ou seja, do tipo de interação entre moléculas e a expressão acima pode ser vista como a equação que a define ${ }^{8}$. Da mesma maneira, Boltzmann argumenta, devemos contar o número de partículas $d \nu$ que após o choque passam a ter uma energia entre $x$ e $x+d x$. Em outras palavras, a variação temporal de $f(x, t)$ é dada por uma equação mestre (na qual a variação de uma grandeza é igual aos ganhos menos as perdas):

$$
f(x, t+\tau) d x=f(x, t) d x-\int d n+\int d \nu .
$$

O cálculo para $d \nu$ leva a

$$
d \nu=\tau f(u, t) d u f(v, t) d v d x \psi(u, v, x) .
$$

A interpretação física é análoga: duas partículas de energias entre $u$ e $u+d u$ e $v$ e $v+d v$ colidem de modo a que uma delas passe a ter uma energia entre $x$ e $x+d x$. Integrando sobre limites apropriados Boltzmann chegou ao resultado para a evolução temporal de $f$ na forma:

$$
\begin{aligned}
\frac{\partial f(x, t)}{\partial t} & =\int_{0}^{\infty} \int_{0}^{x+x^{\prime}}\left[\frac{f(\xi, t)}{\sqrt{\xi}} \frac{f\left(x+x^{\prime}-\xi, t\right)}{\sqrt{x+x^{\prime}-\xi}}\right. \\
& \left.-f(x, t) \sqrt{x} \frac{f\left(x^{\prime}, t\right)}{\sqrt{x^{\prime}}}\right] \\
& \times \sqrt{x x^{\prime}} \psi\left(x, x^{\prime}, \xi\right) d x^{\prime} d \xi
\end{aligned}
$$

Substituindo na expressão acima a distribuição de Maxwell $f_{M}(x, t)=C \sqrt{x} e^{-h x}$ onde $C$ e $h$ são constantes, mostra-se facilmente que $\partial f_{M} / \partial t=0$ e portanto a distribuição de Maxwell é estacionária. Mas, nas palavras do próprio Boltzmann:

Maxwell provou isto e nada mais ${ }^{9}$. Queremos agora olhar o problema por um ângulo muito mais geral. Partindo de uma distribuição inicial de energias cinéticas muito mais geral, nos perguntamos como ela muda com o passar do tempo. Sua evolução temporal é dada pela equação diferencial parcial (5) ... Queremos porém primeiro provar um teorema que forma a base de todas o presente trabalho, a saber o teorema que diz que a grandeza.

$$
E=\int_{0}^{\infty} f(x, t)\left[\log \left(\frac{f(x, t)}{\sqrt{x}}\right)-1\right] d x
$$

nunca pode diminuir 10 se a função $f$ que aparece na integral obedece a equação (5).

A grandeza $E$, mais tarde chamada pelo próprio Boltzmann de $H$, é tal que

$$
\frac{d E}{d t} \leq 0
$$

onde a igualdade só se aplica caso a distribuição $f$ seja a distribuição de Maxwell. Este é o chamado teorema $\mathrm{H}$. Ainda neste artigo ele mostrou para um caso particular que $-E$ era, a menos de uma constante, a entropia de Clausius e apresentou uma dedução alternativa da Eq. (7) em termos de um modelo com energias discretas. Boltzmann em vários de seus trabalhos usou espectros discretos pois, segundo ele, energias discretas eram muito mais "claras e de fácil visualização". Embora Boltzmann afirme em seu artigo que este era um mero recurso matemático que lhe permitia substituir uma equação integrodiferencial por um conjunto

científico, achava incorreta a idéia de publicar duas vezes os mesmos resultados, ele acabou por convencer Boltzmann a escrever apenas um longo artigo, onde então resultados adicionais foram incorporados [6].

${ }^{7}$ Mantive aqui a notação de Boltzmann que usa $x$ para representar a energia cinética, por ele chamada de "força viva".

${ }^{8}$ Para moléculas não interagentes (esferas duras) $\psi$ vale $\left|\vec{v}-\overrightarrow{v^{\prime}}\right| \sin \theta \cos \theta$ (em termos da velocidade $v=\sqrt{2 m x}$ ) e o resultado acima se reduz ao conhecido cálculo do volume do espaço varrido pelas partículas-projétil num tempo $\tau$.

${ }^{9} \mathrm{Ou}$ seja, $\partial f_{M} / \partial t=0$.

${ }^{10} \mathrm{~A}$ ênfase é minha. 
de equações diferenciais ordinárias não lineares e então aplicar o conhecido teorema de Bolzano-Weierstrass, muitos estudiosos da obra de Boltzmann vêem nisto mais do que um simples truque - ela teria servido de inspiração a Planck em 1900, o que tornaria Boltzmann um precursor da mecânica quântica.

De fundamental importância para o desenvolvimento da mecânica estatística em geral foram as críticas dirigidas a seu trabalho, em particular o Wiederkehreinwand de Zermeld ${ }^{11}$ e o Umkehreinwand de Loschmidt ${ }^{12}$. Estas e outras críticas que a elas se somaram tiveram importantes conseqüências na medida em que elas permitiram que Boltzmann não apenas revisasse posições, buscando melhor esclarecer pontos de seu trabalho, como fê-lo também se aprofundar em questões de cunho mais metodológico, lançando as bases da mecânica estatística como hoje a conhecemos. Façamos primeiro uma breve discussão sobre Loschmidt e Zermelo antes de nos voltarmos às outras contribuições de Boltzmann e sua relação com Gibbs. Os paradoxos (ou objeções, como prefiro) podem ser colocados de maneira simples na seguinte forma:

(1) o Umkehreinwand [28]: esta objeção foi muito importante na medida em que ela forçou Boltzmann a reconsiderar sua demonstração da segunda lei. Em sua réplica, Boltzmann não apenas se manifestou sua admiração para com Loschmidt como colocou o paradoxo de forma clara e sucinta 29]. Segundo Loschmidt era impossível deduzir a irreversibilidade a partir das leis reversíveis da mecânica, pois se imaginarmos um sistema que de um estado inicial I em $t=0$ evolui para um estado final mais desordenado $\mathrm{F}$ em $t=\tau$, haverá um aumento da entropia. Contudo, se imaginarmos um estado inicial $-\mathrm{F}$ em $t=0$ onde todas as partículas tem as mesmas posições que tinham em $t=\tau$ do caso anterior mas com todas as velocidades invertidas, então após um tempo $t=\tau$ elas chegarão ao estado $-\mathrm{I}$ com as velocidades ainda invertidas. O movimento obtido é o mesmo que o anterior, mas em sentido retrógrado. Este processo parte de um estado mais desordenado (maior entropia) para um estado mais ordenado (menor entropia) e portanto a entropia diminui com o tempo. Mas, segundo Boltzmann, este argumento era apenas um belo sofisma, pois sua inaplicabilidade advinha do fato que até mesmo o número de moléculas num pequeno volume de um gás era tão assustadoramente grande que uma reversão de todas as velocidades seria algo impensável. Com esta réplica, Boltzmann afirmou de maneira clara o caráter probabilístico da segunda lei, dizendo o quanto [a objeção de Loschmidt] tornara clara a intima relação entre probabilidade e a segunda lei. Isso leva então a outra questão, discutida por Boltzmann em seus Populäre Schriften, a respeito do porquê o Universo é como ele nos parece ser, ou seja, evoluiu a partir de um estado de entro-

\footnotetext{
${ }^{11}$ Objeção do retorno [à configuração inicial].

${ }^{12}$ Objeção da reversibilidade [das velocidades das moléculas].
}

pia muito baixa e por isso observamos um aumento da mesma com o passar das eras. O papel das condições iniciais é sem dúvida crucial mas, como afirma Boltzmann, numa visão ainda não questionada, parece que temos que tomar o estado inicial ordenado do universo como um dos postulados básicos da ciência para o qual ainda não conhecemos uma explicação 30 .

(2) O Wiederkehreinwand [31]: o matemático Zermelo, assistente de Planck, levantou sua objeção baseado no teorema da recorrência de Poincaré que diz que um sistema mecânico sob ação de forças conservativas e cujas posições e velocidades sejam limitadas, obrigatoriamente passará, para algum tempo $t$, em um ponto do espaço de fase tão próximo quanto se queira do ponto em que se encontrava em $t_{0}$. Em dois artigos ele concluiu assim que a teoria cinética seria incapaz de dar uma explicação para o fenômeno da irreversibilidade: em algum momento as condições iniciais do sistema retornarão, o que contradiz a segunda lei pois se $H$ sempre diminui a partir de um dado $t_{0}$, ele teria pelo teorema da recorrência que crescer em algum momento novamente retornando a um valor próximo de $H\left(t_{0}\right)$. A resposta de Boltzmann foi direta e irônica [32]: embora o teorema de Poincaré seja correto, não se pode concluir que a teoria cinética esteja incorreta sem antes se calcular o tempo necessário para que a recorrência ocorra. Para um pequeno volume de gás, da ordem de alguns centímetros cúbicos, este tempo é muitas ordens de grandeza superior à idade do Universo e embora $H$ possa aumentar, a probabilidade que isto ocorra é infinitamente pequena. Concluir que a teoria cinética não vale pelo fato que o teorema de Poincaré é válido seria o equivalente a uma pessoa que, antes de jogar um dado, calculasse a probabilidade de tirar 1000 "uns" seguidos e, achando um valor muito pequeno, chegasse à conclusão que o dado tinha que ser viciado. Novamente, segundo Boltzmann, se confunde improbabilidade com impossibilidade. A frase de Maxwell ...Em outras palavras, a impossibilidade de um decréscimo na entropia não compensado [por um acréscimo] parece reduzir-se a [uma questão] de improbabilidade [33] foi utilizada por Boltzmann na introdução de seu livro sobre teoria cinética 34]. A segunda lei é uma lei estatística e não determinística.

\subsection{Boltzmann e Gibbs}

Do ponto de vista da metodologia e dos fundamentos, Boltzmann fez importantes contribuições à mecânica estatística. Os livros-texto porém, com raras exceções, nos apresentam a mecânica estatística na formulação de Gibbs, por razões que discuto mais detalhadamente ao final desta seção. Assim, a pergunta "quem criou a mecânica estatística?", não raras vezes levantada, deveria na minha opinião ser substituída pela pergun- 
ta "qual o papel que Boltzmann e Gibbs tiveram na criação da mecânica estatística?", pois me parece que as discussões em torno deste tema sempre carregam um forte componente emocional fruto do envolvimento deste ou daquele pesquisador com aspectos particulares das obras destes dois grandes cientistas. Boltzmann foi quem introduziu a idéia de ensembles estatísticos, num artigo de 1884 [35]. Nele Boltzmann levanta a hipótese que era possível interpretar algumas das possíveis distribuições estacionárias como estados de equilíbrio macroscópico. Gibbs, inspirado neste trabalho, estendeuo e sistematizou-o, introduzindo a terminologia hoje usada. O conceito de ensemble estatístico foi chamado por Boltzmann de Monode. A pergunta por ele formulada no trabalho de 1884 pode ser colocada do seguinte modo [18: quais famílias de distribuições estatísticas estacionárias apresentam a propriedade que, ao fazermos uma mudança infinitesimal nos seus parâmetros, as variações em $E, P$ e $V$ são tais que $(d E+P d V) / T$ é uma diferencial exata? A classe de Monoden que satisfazem essa condição é chamada de Orthode, entre as quais há dois tipos: a Ergode (ensemble microcanônico) e a Holode (ensemble canônico). Mas há um outro importante trabalho publicado em 1877 que, se não o mais importante, ao menos é aquele pelo qual Boltzmann é mais lembrado, estando inclusive gravado na lápide de seu túmulo no cemitério central de Viena: a famosa fórmula $S=k \ln W$. Embora Boltzmann nunca tenha escrito a equação nesta forma (nós a devemos a Planck, que inclusive introduziu a constante de Boltzmann na Física 36]), foi nela que Boltzmann, em resposta a Loschmidt, introduziu um "método interessante para o cálculo do equilíbrio térmico" 37. No trabalho com o apropriado título Acerca da relação entre a segunda lei da teoria mecânica do calor e do cálculo de probabilidades com respeito a leis do equilíbrio termodinâmico, Boltzmann mostrou que a entropia de um estado mede sua probabilidade e a entropia aumenta pois sistemas evoluem de estados menos para estados mais prováveis. Para tanto ele novamente recorreu ao seu modelo favorito de energias discretas restritas ao conjunto $0, \epsilon, 2 \epsilon, \cdots, p \epsilon$. Sendo a energia total do gás $\lambda \epsilon$ ( $\lambda$ inteiro) Boltzmann lançou-se à tarefa de determinar o número de maneiras de se distribuir $N$ partículas por entre os níveis tais que $w_{0}$ tinham energia $0, w_{1}$ tinham energia $\epsilon, w_{2}$ tinham energia $2 \epsilon$, e assim por diante, até $w_{p}$. Este novo método combinatório de contagem do número de maneiras de se distribuir partículas por entre níveis evita completamente questões acerca das colisões das partículas e sua dinâmica 8. Um estado molecular específico é compatível com um número $P$ de distribuições de w's, cujo valor é dado por

$$
P=\frac{N !}{w_{0} ! w_{1} ! \cdots w_{p} !} .
$$

Este número segundo Boltzmann era proporcional á probabilidade $W$ da distribuição $\left\{w_{i}\right\}$, em outras palavras,

$$
W=\frac{P}{\sum P},
$$

onde a soma corre sobre todas as distribuições compatíveis com uma energia total fixa e um número total também fixo de partículas. O passo seguinte foi maximizar $P$ sujeito às restrições já mencionadas. Porém, por uma questão técnica (aproximação de Stirling) Boltzmann maximizou ln $P$, a quem ele chamou de Permutabilitätsmass (medida de permutabilidade), e não $P$ diretamente. Ao fazer este cálculo para um gás não interagente ele viu que esta grandeza era nada mais nada menos que a entropia termodinâmica a menos de um fator de escala e uma constante aditiva - e também sua grandeza $E$ de 1872 a menos de um sinal negativo. Como Boltzmann disse, ln $P$ era uma grandeza bem definida quer o estado fosse de equilíbrio ou não [29]:

Imaginemos um sistema arbitrário de muitos corpos tal que o mesmo sofra uma transformação de estado arbitrária, sem que necessariamente os estados inicial e final sejam estados de equilíbrio termodinâmico; então, a medida de permutabilidade $[\ln P]$ de todos os corpos sempre crescerão durante o processo e poderão, no máximo, permanecer constantes, desde que para isso todos os corpos estejam sempre infinitamente próximos de um estado de equilíbrio ao longo do processo (mudança de estado reversível).

A importância deste trabalho pode ser medida nas palavras de Klein [8]

...foi Boltzmann e não Gibbs ou Maxwell que mostrou precisamente como a segunda lei está relacionada à probabilidade, criando assim a ciência da mecânica estatística.

Este artigo também contém, na opinião de estudiosos do assunto, aquilo que hoje chamamos de estatística de Bose-Einstein [38. Face a tantos resultados importantes, ficamos mais uma vez tentados a entender o porquê da predileção por Gibbs e não Boltzmann. Vale lembrar que Boltzmann tinha grande admiração por Gibbs e pelo seu trabalhd ${ }^{13}$. Mas certamente há várias razões históricas e metodológicas que nos permitem entender as razões desta "preferência" 14.

Embora um expositor e professor brilhante, como muitos de seus alunos puderam atestar, Boltzmann era

\footnotetext{
${ }^{13}$ Com relação a isto ver o texto Acerca da Mecânica Estatística publicado nesta edição da RBEF.

${ }^{14}$ Não quero passar aqui a impressão ao leitor que considero o trabalho de Gibbs menor. Para mim ele é um dos grandes heróis da ciência, em particular pelas circunstâncias em que trabalhou e pelo reconhecimento que recebeu apenas postumamente. Minha intenção é discutir uma questão já há muito levantada por historiadores da ciência.
} 
um escritor difícil. Esta dificuldade estava relacionada mais à extensão de seus trabalhos e aos complicados cálculos matemáticos neles contidos, além do que Boltzmann muitas vezes mudava o ponto de vista sem deixar isso claro [8] aos seus leitores. Deste modo seus artigos tornaram-se um desafio para a maioria de seus contemporâneos. O comentário de Maxwell a esse respeito é sintomático [39]:

Ao estudar Boltzmann fui incapaz de compreendê-lo. Ele não me entende em função da minha brevidade, e sua prolixidade representa um problema para mim. Assim vejo-me inclinado a incluir-me no glorioso grupo dos revolucionários que escrevem tudo em mais ou menos seis linhas.

Já Gibbs era considerado um grande estilista, cujo trabalho, em sua formulação abstrata, procurava evitar qualquer hipótese atomística da matéria 40. Este ponto é interessante pois a questão do atomismo, ferrenhamente defendida por Boltzmann, junto com sua predileção por analogias mecânicas foram alguns dos grandes motivos para que sua obra fosse rejeitada. Isso se torna mais evidente quando lembramos que o tratado de Gibbs foi traduzido para o alemão por W. Ostwald com uma introdução de E. Zermelo. Segundo Broda, no final do século XIX reinava na Alemanha uma atitude hostil para com a atomística, coisa que o jovem Planck pôde também sentir pois, embora também não se sentisse por ela atraído, tinha seus problemas com Ostwald e Mach 6]: ...era simplesmente impossível levantar-se contra a autoridade de homens como Ostwald, Helm e Mach. Boltzmann afirma, no prefácio de suas Vorlesungen über Gastheorie [34]:

Seria na minha opinião uma pena para a ciência caso a teoria dos gases [teoria cinética], simplemente fosse esquecida em função da atitude litigiosa que hoje contra ela predomina... o quão impotente uma única pessoa é contra a corrente vigente bem o sei. E ainda, naquilo que estiver ao alcance de minha forças, faço aqui minha contribuição retomando os aspectos mais difíceis e polêmicos da teoria dos gases para que um dia, ao retornarem a ela, não seja necessário descobrir tudo novamente.

O resultado desta hostilidade foi que Gibbs passou a ser lido e melhor apreciado, enquanto Boltzmann não teve o mesmo reconhecimento. Em sua réplica a Zermelo Boltzmann diz, não sem uma certa amargura 34:

Agora, o trabalho do Sr. Zermelo deixa claro que meus artigos no assunto não foram compreendidos, mas estou satisfeito com seu artigo apesar de tudo pois é a primeira evidência que eles receberam um mínimo de atenção na Alemanha.

Ao longo de seus escritos, em particular os Populäre Schriften, são inúmeras as referências a essa rejeição, muitas vezes mascaradas por trás de um comentário irônico.

Cercignani levanta também a hipótese que Planck e principalmente Bohr contribuíram para uma rejeição a Boltzmann 18: Planck por ter tomado o lado de Zermelo na polêmica contra Boltzmann e Bohr por não ter tido grande apreciação pelo trabalho de Boltzmann, chegando a afirmar que Boltzmann estragou tudo ao insistir nas propriedades de sistemas mecânicos. O papel de Bohr é apreciável na medida que ele é considerado um dos mais influentes físicos do século XX.

Poucos cientistas leram Boltzmann também devido ao fato de que ele nunca escreveu um livro onde ele expusesse de maneira clara e ordenada os fundamentos da mecânica estatística. Suas Vorlesungen über Gastheorie [34] não são exatamente um livro onde a mecânica estatística é exposta de maneira sistemática. Trata-se mais de um livro onde casos particulares são estudados para ilustrar importantes resultados obtidos por Boltzmann (como o teorema H). Portanto suas idéias tornaram-se conhecidas através do trabalho de outros, em particular do longo artigo enciclopédico de Tatiana e Paul Ehrenfest 26, cuja versão em inglês apareceu apenas em 1959. O texto dos Ehrenfests, na minha opinião um dos mais importantes da mecânica estatística pela sua clareza e detalhes nas discussões dos fundamentos, é construído justamente em torno das diferenças entre a formulação "antiga" (Boltzmann) e a "moderna" (Gibbs). O texto começa com uma introdução histórica, esclarecendo alguns pontos incompreendidos da obra de Boltzmann, como a questão das diferenças entre a estatística fina e grossa (fine-grained e coarse-grained) e pela primeira introduzem de maneira clara a discussão da hipótese ergódica, um termo por eles introduzido e que Boltzmann apenas comentou en passant em seu artigo de 1872. É interessante notar que os Ehrenfests também discutem a obra de Gibbs sob um certo viés negativo. Segundo Giovanni Gallavotti, esta é a razão principal do desconhecimento de Boltzmann pois ao conversar com alunos de Ehrenfest ${ }^{15}$ acerca de Boltzmann ele nota que a interpretação que estes físicos lhe atribuem na verdade é uma releitura das idéias do próprio Ehrenfest (vale notar que Gallavotti leu Boltzmann no original 41]).

J. Renn sugere que a incompreensão para com Boltzmann deve-se à perspectiva revolucionária de suas idéias 5. Boltzmann era um pensador altamente original e apenas recentemente seu trabalho passou a ser melhor apreciado, em particular o uso de conceitos pro-

\footnotetext{
${ }^{15}$ Essencialmente a escola de mecânica estatística de Leiden, da qual saíram G. Uhlenbeck, E.G.D. Cohen, D. Ter Haar, B. Kahn, entre outros.
} 
babilísticos e modelos com espectros discretos.

Antes de encerrarmos esta seção talvez seja interessante buscarmos a opinião de outros "praticantes" da mecânica estatística além de Cercignani e Gallavotti16 Uma análise extremamente objetiva e de certo modo desinteressada do papel de Boltzmann é o excelente artigo de Joel Lebowitz [42]. Nele, de um modo bastante claro, Lebowitz discute com profundidade o conceito da entropia em Boltzmann e aponta interpretações errôneas fruto da leitura indireta, mostrando que basicamente não há nada em seus trabalhos que mereça correções além daquelas feitas pelo próprio Boltzmann. $\mathrm{Na}$ verdade a profundidade de suas idéias ainda não foi totalmente explorada.

\section{Boltzmann e o eletromagnetismo}

Um pouco menos discutidas na literatura mas no entanto muito importantes foram as contribuições de Boltzmann ao eletromagnetismo. Essas contribuições se deram essencialmente de duas formas: através da divulgação da obra de Maxwell em um livro e palestras, bem como realizando experimentos para comprovar a validade da teoria. Os trabalhos de Boltzmann antecederam Hertz neste aspecto.

No que tange à divulgação, primeiro lembramos que Boltzmann era um grande admirador da obra do físico escocês, uma admiração "herdada" de seu mentor, Joseph Stefan, que tinha a obra de Maxwell em grande conta. Para Boltzmann, Stefan e Helmholtz eram os únicos físicos do continente que realmente tinham entendido a importância da teoria de Maxwell. Talvez em função disto Stefan lhe tenha dado um trabalho nesta área como tema de doutorado além de lhe presentear com uma cópia dos trabalhos de Maxwell e uma vez que eu não entendia sequer uma palavra em inglês, ele me deu também junto [com os artigos] uma gramática da língua inglesa 23. Boltzmann ainda se referindo à importância da ação intermediada por campos, como defendiam Faraday e Maxwell, disse [23]:

Faraday e Maxwell já tinham aberto este outro caminho; a idéia então vigente da existência de dois fluidos elétricos cujas partículas agem a distância uma sobre as outras e que misturadas em proporções iguais cancelam-se mutuamente não lhes convencia. O último [Maxwell], partindo de uma hipótese totalmente diversa, desenvolveu uma nova teoria da eletricidade. Ele supôs que a eletricidade não era um fluido mas um estado de movimento transmitido de um corpo elétrico para um meio específico que o circundava, o éter lu- minífero. Este último então age sobre outros corpos nele imersos, transmitindo assim a impressão que os corpos agem um sobre os outros diretamente através do espaço.

Um outro ponto que unia Boltzmann a Maxwell era a predileção de ambos por modelos mecânicos, o que, como já pude discutir, foi motivo da rejeição de Boltzmann pelos energecistas e Mach. Não é assim de se admirar que Boltzmann tenha publicado um livro sobre a teoria de Maxwell e tenha se pronunciado, sempre que possível, com grande admiração sobre a obra maxwelliana. Em 1895 Boltzmann traduziu e publicou o artigo de Maxwell On Faraday's lines of force na série Klassiker der exakten Wissenschaften, cujo editor era Ostwald ${ }^{17}$.

Do ponto de vista experimental e teórico, Boltzmann publicou trabalhos nesta área particularmente entre 1873 e 1874 mas seu envolvimento com o eletromagnetismo o manteve ocupado por toda sua carreira. Da teoria de Maxwell sabemos que a luz é uma onda eletromagnética e portanto era de se esperar que as propriedades ópticas dos meios pudessem ser explicadas em termos de suas propriedades elétricas. Em particular, Maxwell previra uma relação entre a constante dielétrica $\epsilon$ e o índice de refração $n$ :

$$
\epsilon \sim n^{2} \text {. }
$$

Boltzmann conduziu nestes dois anos uma série de experimentos em cristais de enxofre e gases, estes últimos um verdadeiro desafio experimental. No enxofre a luz se propaga com diferentes velocidades ao longo dos eixos $x, y, z$, tendo portanto diferentes índices de refração nas diferentes orientações, como Boltzmann pôde comprovar 43. Os valores obtidos por Boltzmann para amostras de enxofre foram $\sqrt{\epsilon}=1,960$ para $n=2,040 \mathrm{e}$ para parafina $\sqrt{\epsilon}=1,523$ para $n=1,536$ e $n=1,516$. A dificuldade com relação aos gases se deve ao fato de que sendo sua constante dielétrica muito próxima de 1 , a medida tinha que ser feita com precisão além da terceira casa decimal. Os valores obtidos por Boltzmann para diferentes gases nos dá uma mostra da precisão de seus resultados [43]:

\begin{tabular}{lcc}
\hline Material & $\sqrt{\epsilon}$ & $n$ \\
\hline $\mathrm{Ar}$ & 1,000295 & 1,000294 \\
$\mathrm{CO}_{2}$ & 1,000473 & 1,000449 \\
$\mathrm{H}_{2}$ & 1,000132 & 1,000138 \\
$\mathrm{CO}$ & 1,000345 & 1,000340 \\
$\mathrm{NO}_{2}$ & 1,000497 & 1,000503 \\
Óleo & 1,000656 & 1,000678 \\
Metano & 1,000472 & 1,000443 \\
\hline
\end{tabular}

Com relação ao óleo não foi possível descobrir qual gás Boltzmann usou especificamente (talvez butano). No que tange ao metano, na falta de informações mais

\footnotetext{
${ }^{16}$ Ambos são pesquisadores na área de mecânica estatística e física matemática, com particular ênfase na equação de Boltzmann e teorema $\mathrm{H}$.

${ }^{17}$ Esta série ficou conhecida posteriormente como Ostwalds Klassiker.
} 
específicas podemos imaginar se tratar deste gás, pois Boltzmann se refere genericamente a Sumpfgas, ou seja gás de pântano. Após os trabalhos de Hertz em 1888, Boltzmann desenvolveu uma nova técnica para gerar faíscas num indutor secundário cuja distância até o primário era muito maior do que se houvera conseguido até então, bem como concebeu um novo método interferométrico para determinar o comprimento das ondas, métodos estes que ele usou com grande sucesso nas suas aulas experimentais em Graz [6]. Boltzmann, humildemente, considerava seu próprio trabalho em eletromagnetismo comparável àquele de um "trabalhador braçal" [44]:

Tal trabalhador braçal, cuja tarefa seja apenas a de aplainar o caminho até o edifício, limpar a fachada e colocar aqui e ali uma pedra no alicerce, este sou eu, e com muito orgulho. Pois se ele não existisse, como poderiam os reis construir? Há apenas três coisas que busco para com elas atingir meu objetivo: clareza, concisão e inteligibilidade $e^{18}$.

Um outro aspecto interessante do envolvimento de Boltzmann com o eletromagnetismo foi seu artigo sobre o efeito Hall, descoberto pelo físico americano Edwin Hall. Boltzmann desenvolveu uma teoria para o efeito em um artigo de 1886 45. A teoria para o diamagnetismo também não passou despercebida 46.

Um de seus resultados mais importantes nesta área, uma verdadeira pérola da física teórica nas palavras de Lorentz, é a teoria da dependência da intensidade da radiação eletromagnética com a temperatura, a chamada lei de Stefan-Boltzmann [47. Para Boltzmann tratava-se de reunir num trabalho duas áreas que lhe eram especialmente caras: a termodinâmica e o eletromagnetismo. Dado também seu envolvimento com Stefan e Maxwell não é de se admirar com o interesse de Boltzmann neste problema. Stefan havia estabelecido em 1879 a partir de resultados experimentais que a relação entre a densidade da radiação térmica $e$ e a temperatura $T$ de um corpo negro tinha a forma [4]

$$
e \sim T^{4}
$$

Enquanto trabalhava na resenha de um artigo de H.T. Eddy acerca da radiação térmica como um possível exemplo onde a segunda lei da termodinâmica seria violada, Boltzmann travou conhecimento com o trabalho de A. Bartoli sobre pressão de radiação [1. Motivado pelo trabalho do físico italiano, Boltzmann tentou deduzir a lei de Stefan a partir de argumentos puramente teóricos, partindo da hipótese de que a radiação exercia pressão sobre as paredes de um recipiente que a continha. Combinando eletromagnetismo junto com a primeira e segunda leis da termodinâmica Boltzmann mostrou teoricamente que:

$$
e=\sigma T^{4}
$$

onde $\sigma$ era uma constante de integração. Este trabalho, publicado três anos antes dos experimentos de Hertz, deu novo suporte à teoria de Maxwell e portanto a sua aceitação entre os físicos do continente.

\section{Boltzmann e a mecânica}

A importância que Boltzmann dava à mecânica fica clara pelas palavras da introdução de seu livro neste assunto [8]:

Ela [a mecânica] tem [por tarefa] estudar as leis segundo as quais a totalidade dos movimentos que aparecem na natureza ao nosso redor.

Para Boltzmann a mecânica era hegemônica 49 e sua postura, até certo ponto filosófica, colocou-o em confronto com os energecistas Ostwald, Helm e também o positivista Mach. Basicamente o interesse de Boltzmann com a mecânica surgiu do seu envolvimento com problemas matemáticos advindos da teoria atômica da matéria e mesmo problemas conceituais - que o levaram também a se preocupar com questões de ordem puramente matemática. Seu livro sobre mecânica surgiu com o intuito de expor seus pontos de vista sobre diferentes assuntos: o que realmente significa dizermos que duas partículas são idênticas mas distinguíveis? A resposta, hoje encontrada em bons livros de mecânica, nos mostra que na verdade a questão está relacionada às condições iniciais e da continuidade de seu movimento (em outras palavras podemos acompanhar a história delas e distinguí-las deste modo). Talvez o ponto mais polêmico de seu livro, uma vez que é visto por alguns como contendo um germe da teoria geral da relatividade, é a passagem que diz:

Em todo caso me parece sumamente importante tentarmos ampliar nosso horizonte pela possibilidade que aquilo que nos parece mais certo e próximo na verdade talvez seja correto apenas de forma aproximada. Isto está alinhado com a sugestão que talvez as distâncias entre estrelas fixas só possam ser construídas em um espaço não euclidiano de curvatura muito pequena, que também está relacionado com a lei da inércia, de tal modo que um corpo em movimento e sobre o qual não atuam quaisquer forças voltará depois

\footnotetext{
${ }^{18}$ O termo alemão, usado por Boltzmann, Kärrner significa na verdade "carroceiro". A expressão Kärrnerarbeit ou trabalho de carroceiro, refere-se a um trabalho que envolve muito esforço físico e pouco intelectual. O termo trabalhador braçal me parece uma tradução mais apropriada. Boltzmann faz nesta passagem um jogo de palavras com um poema de F. Schiller, por quem tinha grande admiração. Os artigos, palestras e livros de Boltzmann contém várias citações, explícitas ou implícitas, do poeta alemão.
} 
de eras ao mesmo lugar caso a curvatura em questão seja positiva.

Segundo Klotz concluir pela prioridade de Boltzmann quanto ao germe da teoria da relatividade geral parece um certo exagero [50]. A pergunta talvez seja: até que ponto este trabalho de Boltzmann influenciou Einstein? Embora Einstein cite Boltzmann, ele o faz em conexão com seus trabalhos em mecânica estatística e não em relação à teoria da relatividade, geral ou especial. Boltzmann certamente conhecia o trabalho de Gauss sobre geometrias não euclidianas e seus resultados experimentais acerca da triangulação entre diferentes cidades e podemos imaginar que tivesse essa imagem em mente quando escreveu suas palavras. Mas talvez a história da existência ou não de uma relação entre Boltzmann e a teoria geral da relatividade ainda nos reserve alguma surpresa para o futuro.

Um aspecto interessante do trabalho de Boltzmann em mecânica e de sua relação com a matemática diz respeito a sua predileção por modelos com espectros discretos. $\mathrm{Na}$ verdade Boltzmann acreditava que o cálculo diferencial e integral na verdade eram apenas artifícios matemáticos para tratar de uma realidade discreta. Boltzmann [27]:

Integrais não são reconhecidamente nada mais que uma representação simbólica para somas de infinitos termos infinitamente pequenos...na maioria dos casos a substituição de integrais por soma leva a uma prolixidade inútil...mas há casos em que esta substituição, em função não apenas da generalidade que ela proporciona mas acima de tudo pela clareza com que ela nos apresenta a solução é muito evidente para que nos calemos.

Inúmeros autores interpretam isto como uma presciência do caráter quântico da natureza. Não nos esqueçamos porém que se Boltzmann intuiu o que alguns anos mais tarde Planck e Einstein fizeram, ele nunca colocou de maneira clara o porquê desta sua predileção. No artigo de 1872 acerca do teorema $\mathrm{H}$ a discretização do espectro era um mero recurso matemático, pois como Boltzmann afirma 27]:

Não preciso dizer que no momento não estamos tratando de um problema físico real. É difícil imaginar um experimento no qual o choque entre duas partículas é de tal modo ajustado que após a colisão a energia cinética de ambas tenha mudado por um múltiplo de $\epsilon \ldots$ De qualquer maneira temos a liberdade de posteriormente testar as consequências matemáticas desta hipótese, que nada mais representa que um auxílio

\footnotetext{
${ }^{19} \mathrm{O}$ vôo das aves como fundamento da arte de voar.
}

para facilitar o cálculo de um processo físico. Pois ao final tomamos $\epsilon$ infinitamente pequeno, $p \epsilon$ infinitamente grande tal que a série de energias cinéticas $0, \epsilon, 2 \epsilon, \cdots p \epsilon$ se torna um contínuo, quer dizer, nossa ficção matemática transforma-se no problema físico antes discutido.

Para encerrar, vale lembrar os trabalhos de Boltzmann sobre a teoria da elasticidade e os efeitos de memória em materias elásticos. Boltzmann foi o primeiro teórico a se ocupar deste assunto e é considerado o fundador da chamada mecânica hereditária [51.

\section{Boltzmann e a tecnologia}

Boltzmann foi grande incentivador das tecnologias de ponta de sua era, seja estudando experimentalmente novas tecnologias (o telefone e a possibilidade do telégrafo sem fio), seja através das suas muitas palestras onde, sempre que oportuno, ele chamava a atenção para este ou aquele desenvolvimento. Parece-me, lendo algumas de suas Populäre Schriften, que Boltzmann tentou ter uma atitute pró-ativa, usando da pena e da sua influência como meios para atingir a opinião pública.

Um dos textos que mais chama a atenção no que diz respeito a sua admiração por novas tecnologias e sua forte campanha para a pesquisa aplicada é aquele em que trata da aviação. A palestra Über die Luftschiffahrt [11] é um interessante libelo em que ele se coloca fortemente ao lado da então nascente aviação. A palestra, apresentada em 1894 na mais importante conferência alemã de ciência, nos dá uma idéia da importância que Boltzmann atribuía a este novo meio de transporte - aliás podemos dizer que esta admiração de Boltzmann era conseqüência de sua fascinação com os meios de transporte, em particular os transatlânticos e trens, os quais inúmeras vezes são citados em seus escritos. Para Boltzmann a possibilidade de transportar pessoas e cargas por longas distâncias representava para ele um dos grandes avanços da humanidade.

Seu interesse levou-o a acompanhar de perto os experimentos do engenheiro Otto Lilienthal, um dos pioneiros da aviação. Lilienthal, que praticamente empregava todo o dinheiro de sua pequena empresa no estudo e desenvolvimento de planadores, publicou um livro em 1889, cujo título Der Vogelflug als Grundlage der Fliegekunst ${ }^{19}$ deixa claro sua idéia acerca da maneira como um dia se conseguiria voar 52. Através de longos e exaustivos estudos experimentais e teóricos, Lilienthal chegou à conclusão que o caminho mais rápido para se conseguir voar seria desenvolvendo um aparelho que imitasse o mais fielmente possível o vôo dos pássaros. Seu livro, uma mistura de cálculos teóricos e resultados experimentais, pode hoje ter apenas interesse histórico, mas alguns de seus resultados e principalmente os pla- 
nadores desenvolvidos depois de abandonar a idéia de um avião que batesse asas são capazes de voar influenciaram gerações de pioneiros da aviação. Mais importante talvez seja o fato de que Lilienthal descobriu, experimentalmente, a importância do perfil curvo das asas como fator determinante para a sustentação, embora sua explicação física para este fato estivesse errada. Interessante neste texto de Boltzmann é o fato de que, apesar de seu grande respeito por Lilienthal, ele não deixa de apontar algumas daquelas que considera concepções técnicas incorretas do engenheiro. Por exemplo Boltzmann diz que mais eficiente que o bater de asas seria prover o avião com uma hélice, pois esta permitiria que o aparelho se deslocasse horizontalmente enquanto a "resistência" do ar garantiria a sustentação. Mas mais interessante é talvez o fato que Boltzmann chame a atenção para os sacrifícios humanos envolvidos na perigosa empreitada de testar os aparelhos. Boltzmann estava seguro de que isso não seria possível sem o risco de vidas humanas e aquele que conseguisse finalmente voar poderia ser colocado ao lado de um herói como Colombo, por quem Boltzmann tinha grande admiração (além dos poetas Schiller, do compositor Beethoven e de Charles Darwin, para ele o homem cujo trabalho seria lembrado como o mais importante do século XIX). Não havia outro meio, o progresso exigia sacrifícios. Coincidentemente dois anos após estas palavras Lilienthal se acidentou durante um teste e veio a falecer em função dos graves ferimentos de uma queda de aproximadamente 15 metros.

\section{A literatura boltzmanniana}

Há duas maneiras de acessarmos as obras de Boltzmann. A primeira, que seria a leitura direta de seus artigos, esbarra em uma série de dificuldades, a maior delas talvez linguística. O alemão de Boltzmann está em um nível inacessível para aqueles que detêm apenas um conhecimento básico da língua. Há poucas traduções de Boltzmann para o inglês, a maioria delas extratos de artigos específicos. Em Brush e Hall [53] podemos encontrar o importante artigo de 1872 [27] e o artigo de 1877 [29]. Seu livro Vorlesungen über Gastheorie foi publicado em inglês [34]. Os mesmos artigos que encontramos em Brush e Hall podemos encontrar, em italiano, numa tradução de Massimiliano Badino 54.

A segunda maneira de lermos Boltzmann seria fazendo-o através daqueles que estudaram sua obra ou tiveram com ele um contato direto. Entre os últimos o trabalho de P. e T. Ehrenfest ainda é a melhor fonte de informações [26]. Como já discutido, muitos estudiosos de Boltzmann acreditam que P. Ehrenfest em particular deixou muito de suas próprias idéias, o que na minha opinião não pode ser visto com algo negativo, muito pelo contrário. Ehrenfest não é um mero "repetidor" de idéias e, no que diz respeito à elucidação da abordagem de Boltzmann e da comparação com as idéias de Gibbs, o livro ainda é imbatível. A parte de comentários ao final, escrita quase que integralmente por Tatyana Ehrenfest após a morte de seu marido, é praticamente um livro à parte. Poucos livros de mecânica estatística discutem os fundamentos como os livros de Ehrenfest - talvez o único a que podemos comparar é o de Khinchin, que também conhecia profundamente a obra de Boltzmann [55].

Entre as obras mais recentes podemos destacar a série de artigos de especialistas publicados na Ref. [56], o livro de Broda [6] e o mais recente de Cercignani [1]. O primeiro livro nos dá um panorama geral da vida e obra de Boltzmann, restringindo-se não apenas à Física mas também à Filosofia e principalmente a relação entre Boltzmann e seus contemporâneos. Trata-se de uma obra altamente recomendável, embora alguns dos artigos estejam em alemão, o que pode tornar a leitura difícil. Broda, estudioso da vida de Boltzmann, escreve um livro onde de maneira acessível a um não especialista trata da obra e vida de Boltzmann. O livro de Cercignani, mais recente, não obstante seus méritos, alterna bons momentos e alguns não tão bons, principalmente pela profundidade da exposição. Alguns aspectos da obra de Boltzmann são tratados superficialmente, ao passo que outros de maneira bastante profunda, o que reflete um pouco o fato de Cercignani ser um respeitadíssimo pesquisador na área da equação de Boltzmann.

Entre as obras sobre aspectos mais específicos do legado de Boltzmann me parece que o artigo de Martin Klein ainda é o melhor 8. Klein teve contato direto com T. Ehrenfest em Dublin, onde realizou seu pósdoutorado com E. Schrödinger após concluir um doutorado com L. Tisza [57]. Klein esteve assim em contato direto com pessoas que conheciam Ehrenfest profundamente e seu interesse por este físico, que culminou numa importante biografia, fez dele um dos mais respeitados estudiosos da mecânica estatística ao lado de S.G. Brush. Klein, como professor em Yale, realizou também importantes estudos sobre J.W. Gibbs, o que lhe permite falar com grande autoridade sobre os dois mais importantes nomes da mecânica estatística.

Uma outra importante fonte de informações sobre Boltzmann é o livro editado por Walter Höflechner Ludwig Boltzmann: Vida e Correspondências em alemão [58]. Esta obra, inicialmente concebida como os volumes 9 e 10 das obras coligidas de Boltzmann [56. acabou sendo editada em apenas um volume pela Universidade de Graz, uma vez que o projeto original não foi concluído. Na primeira parte de sua obra Höflechner escreveu uma biografia da vida acadêmica de Boltzmann, com suas várias estadias por diferentes universidades. Nela não faltam detalhes salariais, cartas oficiais das universidades e réplicas de Boltzmann, tudo acompanhado de farto material bibliográfico. A segunda parte do livro reproduz a correspondência de Boltzmann. 
A bibliografia ao final contém todos os artigos e obras de referência por mim consultadas. Sempre que possível, coloquei referências dos textos em inglês quando estes existiam ao lado dos originais alemães. Alguns poucos artigos podem ser encontrados em repositórios da rede mundial de computadores.

\section{Conclusão}

Há 100 anos morria, de forma trágica e prematura, um dos mais importantes físicos teóricos do século XIX. Ludwig Eduard Boltzmann, embora conhecido principalmente pelo seu trabalho em mecânica estatística, que junto com Gibbs e Maxwell ajudou a fundar, foi um físico polivalente, realizando trabalhos teóricos e experimentais nas mais diversas áreas da Física. Seus trabalhos em Eletromagnetismo, pouco explorados pelos historiadores da ciência, contribuíram significativamente para a aceitação do trabalho de Maxwell nos países de língua germânica, mérito que divide com Hertz. Suas contribuições à mecânica, fruto de seu envolvimento com questões dos fundamentos da mecânica estatística, abriram o caminho para uma série de trabalhos de gerações posteriores. Seu método estatístico, baseado em cálculos de análise combinatória, tem recebido nos últimos anos uma maior atenção face a originalidade de suas idéias. Procurei neste artigo discutir aquelas que me parecem suas contribuições mais importantes em Física.

\section{Agradecimentos}

Vários colegas, no Brasil e na Alemanha, contribuíram muito para minha educação acerca de Boltzmann. No Brasil, os Profs. Nelson Studart e Augusto A.A. Videira deram inúmeras sugestões que muito contribuíram para o presente texto. Na Alemanha, W. Kinzel, H. Hinrichsen, J. Renn e M. Badino foram fundamentais para uma melhor apreciação da obra de Boltzmann. À Fundação Alexander von Humboldt agradeço o apoio financeiro que me permitiu participar do Boltzmann Symposium em Viena.

\section{Apêndice: Artigos de Boltzmann por área temática}

A tabela a seguir é uma compilação dos artigos científicos de Boltzmann publicados entre os anos de 1865 e 1905 . Não constam desta lista os livros de Boltzmann, a saber: Vorlesungen über Maxwells Theorie der Elektricität und des Lichtes, 2 v. (1891); Vorlesungen über Gastheorie, 2 v. (1898); Vorlesungen über die Prinzipe der Mechanik, 2 v. (1904); o artigo de revisão da Enzyklopaedie der mathematischen Wissenschaften intitulado Kinetische Theorie der Materie, em colaboração com J. Nabl; o livro Das mechanische Potential und eine Theorie der Figur der Erde, compilado em 1908 por H. Buchholz a partir de notas de aula. Do total, 139 artigos foram publicados em periódicos e 22 compilados na forma de livro. Entre os primeiros, 12 são experimentais. A soma por tema pode não corresponder à soma total uma vez que Boltzmann em alguns casos tratou de diferentes assuntos em um mesmo artigo.

\begin{tabular}{|c|c|c|c|c|c|c|c|}
\hline & Termo & $2^{\mathrm{a}}$ Lei & Equil. & Gases & Radiação & Gerais & Total (139) \\
\hline $\begin{array}{l}\text { Teoria Cinética } \\
\text { Termodinâmica }\end{array}$ & 8 & 8 & 34 & 18 & 5 & 12 & $79(57 \%)$ \\
\hline & Dielet. & Maxwell & Hall/Termoelet. & & & & \\
\hline \multirow[t]{2}{*}{ Eletricidade } & 7 & 5 & 5 & & & 14 & $31(22 \%)$ \\
\hline & Hidro & Elast. & Métodos & & & & \\
\hline \multirow[t]{2}{*}{ Mêcanica } & 2 & 4 & 1 & & & 4 & $11(7 \%)$ \\
\hline & Fis. Mat. & Aparatos & & & & & \\
\hline \multirow[t]{2}{*}{ Outros } & 2 & 1 & & & & 5 & $8(6 \%)$ \\
\hline & Opt. & Ac. & & & & & \\
\hline Óptica/Acust. & 1 & 3 & & & & & $4(3 \%)$ \\
\hline Energetismo & 2 & & & & & & $2(1.5 \%)$ \\
\hline Matemática & 4 & & & & & & $4(3 \%)$ \\
\hline Epistemologia & 11 & & & & & & \\
\hline Discursos & 4 & & & & & & $1(0.5 \%)$ \\
\hline Artigos populares & 8 & & & & & & \\
\hline
\end{tabular}

(i) Em teoria cinética e termodinâmica estão os resultados em termodinâmica propriamente dita, os importantes artigos sobre o análogo mecânico da $2^{\mathrm{a}}$ lei da termodinâmica e equilíbrio termodinâmico (i.e. a equação de Boltzmann). Também sob "gases" encontramos trabalhos acerca do calor específico (4), viscosidade (5), difusão (2) e equação de estado e dissociação (7) dos mesmos. Em radiação térmica Boltzmann tratou do problema da radiação do corpo negro e alguns aspectos da irreversibilidade do processo de radiação térmica. Os resultados gerais englobam teorias para resultados experimentais bem como cálculos do livre caminho médio de moléculas.

(ii) Eletricidade: aqui estão contidos os artigos experimentais acerca da determinação da constante dielétrica de materiais, discussões sobre a teoria de Maxwell, o efeito Hall e o efeito termoelétrico bem como alguns problemas mais práticos acerca da interferência de ondas eletromagnéticas e os experimentos de H. Hertz. 
(iii) Mecânica: particularmente hidrodinâmica e teoria da elasticidade. Em métodos formais há um artigo sobre a formulação lagrangiana, em resultados gerais problemas de interesse prático ou discussões de cunho epistemológico (sobre H. Hertz).

(iv) Resultados gerais em Física: aqui podemos encontrar alguns trabalhos de Boltzmann em física matemática, a descrição de aparatos por ele criados para ilustrar leis físicas bem como outros resultados, normalmente comentários sobre artigos de outros físicos ou desenvolvimentos teóricos para resultados experimentais recém publicados por terceiros.

(v) Óptica e acústica: 2 artigos experimentais sobre a possibilidade de se fotografar oscilações em colunas de ar. Um artigo teórico sobre polarização e um artigo sobre história.

(vi) Energetismo: aqui encontramos dois artigos publicados por Boltzmann refutando a teoria de Helm e Ostwald.

(vii) Matemática: artigos de Boltzmann em matemática pura (equações diferenciais, séries de Fourier).

\section{Referências}

[1] C. Cercignani, Ludwig Boltzmann: The Man Who Loved Atoms (Oxford University Press, Oxford, 1998).

[2] D. Flamm, Life and Personality of Ludwig Boltzmann, em 59, p. 3-16 (D. Flamm, físico teórico, era neto de Boltzmann).

[3] D. Flamm, Aus dem Leben Ludwig Boltzmanns, em [56, p. 21-56.

[4] M. Badino, comunicação pessoal ao autor.

[5] J. Renn, comunicação pessoal ao autor.

[6] E. Broda, Ludwig Boltzmann: Mensch, Physiker, Philosoph (Franz Deuticke Verlag, Viena, 1983). Este livro foi lançado em inglês com o título Ludwig Boltzmann: Man, Physicist, Philosopher (Ox Bow Press, Nova York, 1983).

[7] L. Boltzmann, Wissenschaftliche Abhandlungen von L. Boltzmann, editado por F. Hasenöhrl (J. Barth Verlag, Leipzig, 1909). Esta obra, em três volumes, traz todos os artigos de Boltzmann publicados em periódicos. Reeditada em 1968 pela Chelsea Publishing Company, Nova Iorque.

[8] M.J. Klein, The development of Boltzmann's Statistical Ideas, em 59, p. 157-211.

[9] K.V. Meyenn, Boltzmann als Kritiker und Rezentist, em 56, p. $97-127$.

[10] L.E. Boltzmann, Der Zweite Hauptsatz der Mechanischen Wärmetheorie, em 60, p. 26 (ed. brasileira, p. 25).

[11] L.E. Boltzmann, Über Luftschiffahrt (Verhandlungen der Gesellschaft Deutscher Naturwissenschaftler und Ärzte, Leipzig, 1894). Ver tradução nesta edição da RBEF.

[12] R. Musil, Um Homem sem Qualidades (Der Mann ohne Eigenschaften) (Ed. Nova Fronteira, São Paulo, 2006), $2^{\mathrm{a}}$ ed., tradução de Carlos Abbenseth e Lya Luft.

[13] S.B. Volchan, A probabilidade na mecânica estatística clássica, nesta edição da RBEF.

[14] A.A.P. Videira, Boltzmann, tísica teórica e representação, nesta edição da RBEF.

[15] C.C. Laranjeiras e J.R.N. Chiappin, A heurística de Boltzmann e a emergência do programa mecânico estatístico, nesta edição da RBEF.

[16] L.E. Boltzmann, Über die mechanische Bedeutung des zweiten Hauptsatzes der Wärmetheorie, Wiener Berichte 53, 195 (1866). Em 7, v. I, p. 10-35.
[17] L.E. Boltzmann, Über die Bewegung der Elektrizität in krummen Flächen, Wiener Berichte 52, 214 (1865). Em 7], v. I, p. 1-8.

[18] C. Cercignani, Boltzmanns Vermächtnis, Physik Journal 5, 47 (2006), e referências inclusas.

[19] E. Schrödinger, The Statistical Law in Nature, Nature 153, 704 (1944). Citado em 8. Ver também E. Schrödinger em Geist und Materie (Vieweg Verlag, Wiesbaden, 1959). A edição original deste livro é inglesa: Mind and Matter (Cambridge University Press, Cambridge, 1944).

[20] Y.M. Guttmann, The Concept of Probability in Statistical Physics (Cambridge University Press, Cambridge, 1999).

[21] H. Reichenbach, The Direction of Time (Dover Publications, Mineola, 2000) (reedição da obra publicada originalmente pela University of California Press em 1956).

[22] H.D. Zeh, The Physical Basis of the Direction of Time (Springer Verlag, Berlin, 1999), $2^{\mathrm{a}}$ ed.

[23] L.E. Boltzmann, Josef Stefan, em 60], p. 59 (na edição brasileira este texto não consta).

[24] L.E. Boltzmann, Studien über das Gleichgewicht der lebendigen Kraft zwischen bewegten materiellen Punkten, Wiener Berichte 58, 517 (1868). Em 7, v. I, p. 49-96.

[25] M. Badino, The foundational role of ergodic theory, Max Planck Institute for the History of Science in Berlin, preprint 292 (2006). Este preprint pode ser obtido em www.mpiwgberlin.mpg.de/en/forschung/preprints.html.

[26] P. Ehrenfest e T. Ehrenfest, Begriffliche Grundlagen der statistischen Auffassung in der Mechanik, Enzyklopädie der Mathematischen Wissenschaften (Bd. IV, Leipzig, 1911). A versão em inglês, The Conceptual Foundations of the Statistical Approach in Mechanics foi traduzida por M.J. Moravcsik e publicada pela Cornell University Press, Ithaca, em 1959.

[27] L.E. Boltzmann, Weitere Studien über das Wärmegleichgewicht unter Gasmolekülen, Wiener Berichte 66 , 275 (1872). In 7 v. I, p. 306-402.

[28] J. Loschmidt, Über den Zustand des Wärmegleichgewichtes eines Systems von Körpern mit Rucksicht auf die Schwerkraft, Wiener Berichte 73, 139 (1876).

[29] L.E Boltzmann, Über die Beziehung eines allgemeinen mechanischen Satzes zum zweiten Hauptsatze der Wärmetheorie, Wiener Berichte 75, 67 (1877). Em [7, v. II, p. 164-223.

[30] L.E. Boltzmann, Über statistische Mechanik. Ver a tradução nesta edição da RBEF. 
[31] E. Zermelo, Über einen Satz der Dynamik und die mechanische Wärmetheorie, Annalen der Physik 57, 485 (1896); Über mechanische Erklärungen irreversibler Vorgänge. Eine Antwort auf Hrn. Boltzmanns Entgegnung, Annalen der Physik 59, 793 (1896).

[32] L.E. Boltzmann, Entgegnung auf die wärmtheoretischen Betrachtungen der Hrn. E. Zermelo, Annalen der Physik 57, 773 (1896). Em [] v. III, p. 567-578; Zu Hrn. Zermelos Abhandlung, Über die mechanische Erklärung irreversibler Vorgänge, Annalen der Physik 60, 392 (1897). Em [7] v. III, p. 579-586.

[33] J.C. Maxwell, Theory of Heat (Dover Publications, Mineola, 2001).

[34] L.E Boltzmann, Vorlesungen über Gastheorie (J.A. Barth Verlag, Leipzig, 1898), em dois volumes. Há uma versão em inglês, Lectures on Gas Theory (Dover $\mathrm{Pu}$ blishing, Mineola, 1995). Reproduzido em [56] como v. II.

[35] L.E. Boltzmann, Ableitung des Stefanschen Gesetzes, bettrefend die Abhängigkeit der Wärmestrahlung von der Temperatur aus der elektromagnetischen Lichttheorie, Annalen der Physik 22, 29 (1884). Em [7], v. III, p. $118-121$

[36] M. Planck, Wissenschaftliche Selbstbiographie (J. Barth Verlag, Leipzig, 1948). Reeditada em Acta Historica Leopoldina 19, 1 (1990).

[37] L.E. Boltzmann, Über die Beziehung zwischen den zweiten Hauptsatze der mechanischen Wärmetheorie und der Wahrscheinlichkeitsrechnung respektive den Sätzen über das Wärmegleichgewicht, Wiener Berichte 76, 373 (1877). Em [7, v. II, p. 164-223.

[38] A. Bach, Boltzmann's probability distribution of 1877, Arch. Hist. Exact Sciences 41, 1 (1990).

[39] Em [18, p. 140.

[40] J.W. Gibbs, Elementary Principles in Statistical Mechanics, Developed with Special Reference to the Rational Foundations of Thermodynamics (Yale University Press, New Haven, 1902).

[41] G. Gallavotti, Ergodicity, ensembles, irreversibility in Boltzmann and beyond, J. Stat. Phys. 78, 1571 (1995). Com relação à leitura de originais, comunicação pessoal ao autor.

[42] J.L. Lebowitz, Boltzmann's entropy and time's arrow, Physics Today 46, 32 (1993).

[43] L.E. Boltzmann, Experimentelle Bestimmung der Dielektrizitätskonstante von Isolatoren, Wiener Berichte 67, 17 (1874). Em [7, p. 411-471; Experimentelle Bestimmung der Dielektrizitätskonstante einiger Gase, Wiener Berichte 69, 795 (1879), em 7], p. 537-555.
[44] Vorlesungen über Maxwells Theorie der Elektricität und des Lichtes, (J.A. Barth Verlag, Leipzig, 1891), em dois volumes.

[45] L.E. Boltzmann, Zur Theorie des von Hall entdeckten elektromagnestischen Phänomens, Wiener Berichte 94, 644 (1886). Em 7] v. III p. 187-211.

[46] L.E. Boltzmann, Über die auf Diamagnete wirksamen Kräfte, Wiener Berichte 80, 687 (1879). Em [7] v. II p. 330-354; Entwicklung einer zur Bestimmung der Diamagnetizierungszahl nützlichen Formel, Wiener Berichte 83, 576 (1881). Em [7] v. II p. 576-587.

[47] J. Stefan, Über die Beziehung zwischen der Wärmestrahlung und der Temperatur, Wiener Berichte 79, 391 (1879).

[48] L.E. Boltzmann, Vorlesungen über die Prinzipe der Mechanik (J.A. Barth Verlag, Leipzig, 1904).

[49] L. Boltzmann, Über die Prinzipien der Mechanik, em 60 p. 308-337 (ed. brasileira p. 125-154).

[50] H. Klotz, Did the germ of general relativity come from Boltzmann?, em [56, p. 355-361.

[51] L. Boltzmann, Zur Theorie der elastischen Nachwirkung, Wiener Berichte 70, 275 (1874). Em [7, v. I, p. $616-644$.

[52] O. Lilienthal, Der Vogelflug als Grundlage der Fliegekunst, Editora Dr. Martin Sändig oHG, Wiesbaden, 1965.

[53] S.G. Brush e N.S. Hall, eds., Kinetic Theory of Gases: An Anthology of Classic Papers With Historical Commentary (Imperial College Press, London, 2003).

[54] M. Badino, Ludwig Boltzmann: Fisica e Probabilitá (Melquiades, Milão, 2005).

[55] A.I. Khinchin, Mathematical Foundations of Statistical Mechanics (Dover Publications, Mineola, 1960).

[56] R. Sexl and J. Blackmore, eds., Ludwig Boltzmann Gesamtausgabe (Friedrich Vieweg und Sohn, Braunschweig/Graz, 1982), v. 8 (edição das obras de Boltzmann em 9 volumes. Até o momento apenas 3 foram editados).

[57] M.J. Klein, comunicação pessoal ao autor.

[58] Ludwig Boltzmann: Leben und Briefe (Akademische Druck-u. Verlagsanstalt, Graz, 1994).

[59] E.G.D. Cohen e G. Uhlenbeck, eds., The Boltzmann Equation: Theory and Application (Springer Verlag, Vienna, 1973).

[60] L.E. Boltzmann, Populäre Schriften (Ambrosius Barth Verlag, Leipzig, 1905) (Escritos Populares, tradução e notas de A.A. Passos Videira, Ed. Unisinos, Novo Hamburgo, 2005.) 